\section{Access to prenatal care: assessment of the adequacy of different indices}

\author{
Acesso à assistência pré-natal: avaliação da \\ adequação por diferentes índices
}

\author{
Acceso a la atención prenatal: la evaluación de la \\ adecuación de diferentes índices
}

Edson Theodoro dos Santos Neto ${ }^{1}$ Adauto Emmerich Oliveira 1

Eliana Zandonade 2

Maria do Carmo Leal 3
${ }^{1}$ Departamento de Medicina Social, Universidade Federal do Espírito Santo, Vitória, Brasil.

2 Programa de Pós-graduação em Saúde Coletiva

Universidade Federal do Espírito Santo, Vitória, Brasil.

${ }_{3}^{3}$ Escola Nacional de Saúde Pública Sérgio Arouca,

Fundação Oswaldo Cruz, Rio de Janeiro, Brasil.

Correspondence E. T. Santos Neto Departamento de Medicina Social, Universidade Federal do Espírito Santo.

Av. Marechal Campos 1468 , Vitória, ES

29040-090, Brasil. edsontheodoro@uol.com.br

\section{Abstract}

This study aimed to compare the evaluation of adequate access to prenatal care according to different indices. Data to construct the indices were obtained from 1,006 patient interviews, prenatal cards, and medical charts for postpartum women who had been admitted for childbirth at maternity hospitals in Greater Metropolitan Vitória, Espírito Santo State, Brazil, from April to September 2010. The various indices for the evaluation of prenatal care were compared to the Kotelchuck index (1994) as the standard reference. Prevalence rates for adequacy were calculated as were agreement, sensitivity, specificity, predictive values, accuracy, and likelihood ratios. The Takeda index showed the highest prevalence of adequacy (55.8\%). The highest agreement was between the indices proposed by Villar et al. and Rosen et al. (adjusted kappa =0.84). The study concludes that the Carvalho \& Novaes index and the Brazilian Ministry of Health index are relevant for assessing adequate access to prenatal care.

Maternal and Child Health; Health Evaluation; Maternal-Child Health Services; Health Services Accessibility

\section{Resumo}

O objetivo deste estudo foi comparar a avaliação da adequação do acesso à assistência pré-natal por diferentes indices. As informações para compor os índices foram retiradas de 1.006 formulários de pesquisa, cartões de gestantes e prontuários médicos de puérperas, que se internaram por ocasião do parto em maternidades da Região Metropolitana da Grande Vitória, Espírito Santo, Brasil, no período de abril a setembro de 2010. Os indices de avaliação do pré-natal foram comparados ao índice de Kotelchuck (1994), o padrão de referência. Prevalências de adequação foram calculadas e análises de concordância, sensibilidade, especificidade, preditividade, acurácia e razões de verossimilhança foram realizadas. A maior prevalência de adequação foi encontrada pelo índice Takeda (55,8\%). A maior concordância ocorreu entre os indices de Villar et al. e Rosen et al. (kappa ajustado =0,84). Conclui-se que o índice de Carvalho e Novaes e o índice do Ministério da Saúde do Brasil são relevantes para avaliar a adequação do acesso à assistência pré-natal.

Saúde Materno-Infantil; Avaliação em Saúde; Serviços de Saúde Materno-Infantil; Acesso aos Serviços de Saúde 


\section{Introduction}

The first forms of state intervention in maternal

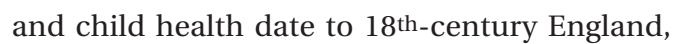
through policies focused on childhood and medicalization of childbirth and family health, with the aim of producing more children with decent living conditions, thus imposing a set of obligations on parents and children 1.

Although permeated by the implicit objective of strengthening a social body capable of fomenting birth and offering support for industrial expansion, such health policies favored important social development, as proven by the control and eradication of various infectious diseases, fostering both increasing life expectancy and important growth in the world population 2 .

In this phase of the life cycle, prenatal care is an outstanding measure to prevent or decrease the risk of death for both mothers and infants 3 . In prenatal care, health professionals can detect and intervene in risk factors, avoiding health complications for mothers and infants. Studies in medium and low-income countries have indicated that few prenatal visits are a significant risk factor for increased perinatal mortality 4 and longer stay for newborn infants in intensive care units 5 .

Still, numerous prenatal visits are not always synonymous with effective gestational care. In low-risk pregnancies, evidence suggests that few prenatal visits can be as effective as many visits, as long as the proper interventions are performed at the proper time according to each pregnant woman's needs 6 .

Therefore, various epidemiological studies to evaluate prenatal care have been conducted to shed light on its quality, using as criteria the timing in the pregnancy when follow-up by health services begins, the total number of visits, gestational age at each visit, and physical, clinical, laboratory, and educational procedures that qualify the assessment of adequate care $7,8,9$.

The attempt to develop methods to assess prenatal care is not new 10,11 . Criteria for assessing adequate prenatal care underwent various changes over the years, reflecting the development of new technological and diagnostic tools and scientific evidence in maternal and child health 12,13 .

Methods for assessing prenatal care can be classified as: indices that measure access, defined as users' entry into health services and continuity of care 14 and indices that assess the adequacy of the process of care, defined as activities involving health professionals and patients according to technical, scientific, and/or administrative standards 15 . These indices can be used separately or jointly in prenatal health services assessment, as partial methods for measuring quality of care.

The indices that evaluate access to prenatal care can employ different criteria for defining adequate access. Thus, the use of different indices can produce contradictory results even when assessing the same prenatal care service. This has direct repercussions on the planning and implementation of maternal and child health policies in public health services. In this context, the current study proposes to compare the assessment of adequacy of access to prenatal care according to different indices.

\section{Methods}

The sample included all women admitted for delivery at public and outsourced maternity hospitals under the Brazilian Unified National Health System (SUS) in Greater Metropolitan Vitória, Espírito Santo State, Brazil, from April to September 2010.

The data were collected through face-to-face interviews with the mothers in the postpartum period, analysis of their respective prenatal cards, and medical charts at the health establishment where the delivery was performed. The sample size was set according to the sample size formula to estimate the proportion of live births covered by 7 or more prenatal visits, considering the population of 17,980 live births in 2007, an expected proportion of $58.2 \%$, corresponding to the municipality (county) within Greater Metropolitan Vitória with the lowest coverage rate, both according to the Information System on Live births (SINASC). The target precision was $4 \%$, design effect 1.5 , and $5 \%$ level of significance.

The calculations resulted in a sample size of 849 women. The total was increased by some $30 \%$ to cover possible losses and refusals, resulting in requests for interviews with 1,131 postpartum women in the maternity hospitals. Considering the differences in the contingent of live births between the municipalities, the sample's representativeness was guaranteed by stratification according to the following proportions: Cariacica (22.6\%), Fundão (1\%), Guarapari (6.3\%), Serra (26.3\%), Viana (3.7\%), Vila Velha $(22.2 \%)$, and Vitória (17.9\%).

Seven field interviewers were selected after passing theoretical and practical tests in the interviewers' training course conducted by faculty members at the Federal University in Espírito Santo (UFES) and the Sergio Arouca National School of Public Health, Oswaldo Cruz Foundation (ENSP/Fiocruz). A pilot study was also conducted with 67 postpartum women - not 
included later in the main study - to improve the interview format and interviewers' training.

The interviewers visited all eight maternity hospitals included in the study at least once a week, visiting the women in the postpartum period to interview them on their prenatal care. On the days of these visits, the interviewers listed all the postpartum women living in one of the municipalities of Greater Metropolitan Vitória and then conducted systematic sampling to select the women to be visited for potential interviews. This method was followed until the total sample was reached.

At this first contact, the interviewers asked about the possibility of conducting the interview and whether the woman had her "Prenatal Card" on her person, excluding: women who had done their prenatal care entirely or partially in the private system or in other municipalities outside Greater Metropolitan Vitória, as well as postpartum women less than 12 hours after undergoing cesareans.

After identifying the selected women, the interviewers explained the study's objectives and asked the woman to sign the informed consent form, according to the guidelines approved by the Institutional Review Boards of the UFES Center for Health Sciences on November 4, 2009, case no. 93/2009. Data from the woman's medical chart were transcribed onto the interview form, the Prenatal Card was copied in full, and the woman was interviewed. The study variables were constructed on the basis of the three sources to increase the completeness of the information.

The information on the beginning of the prenatal care and the gestational week or month of the visits was obtained, considering the recording date on the Prenatal Card and the newborn's date of birth and gestational age at birth recorded on the medical chart. In addition, the total number of prenatal visits was obtained from the counts on the Prenatal Cards with the dates of the visits and recording of at least one procedure, while data on parity were based on the information provided by the mother during the interview.

Some evaluation indices have intermediate categories and levels to classify prenatal care, but the current study adopted a dichotomous classification (adequate versus inadequate). However, this study considered the components of indices related to access, defined as the users' entry into health services and continuity of the care 14 which refers generically to the timing of initiation of prenatal care and the number of visits.

The indices for assessing access to prenatal care were calculated with the data obtained from a cross-sectional epidemiological study of postpartum women in Greater Metropolitan Vitória.
The index by Ciari Jr. et al. ${ }^{10}$ defines adequate prenatal care as beginning in the first trimester and a ratio of visits performed to five expected visits greater than or equal to $80 \%$.

According to the index by Kessner et al. ${ }^{11}$ of the United States Institute of Medicine, for a 36week pregnancy, adequate prenatal care includes a visit before the $4^{\text {th }}$ month and a minimum total of nine visits.

According to the Revised Graduated Prenatal Care Utilization Index (revised GINDEX), proposed by Alexander \& Cornely 16, prenatal care should also begin before the $4^{\text {th }}$ month, but the total number of visits should accompany the duration of the pregnancy. In pregnancies up to 36 weeks, nine visits would be adequate. However, starting at 36 weeks the woman should have one visit a week until delivery 16 .

The index created by the United States Public Health Service Expert Panel on Prenatal Care, described by Rosen et al. 17, defines adequate prenatal care as beginning up to the eighth gestational week, with a total of nine visits for women in their first pregnancy and seven visits for multiparous women. The Takeda index 18, a modification of the Kessner index 11, defines adequate access to prenatal as beginning up to the $20^{\text {th }}$ gestational week, with at least six visits.

The Adequacy of Prenatal Care Utilization (APNCU) index, formulated by Kotelchuk 19, analyzes the number of visits during prenatal care according to the American College of Obstetricians and Gynecologists, adjusted according to gestational age at initiation of care, which should be up to the $4^{\text {th }}$ month, and to gestational age at delivery. The index considers the ratio between the number of visits performed and the expected number of visits. Prenatal care is considered adequate when the ratio is greater than or equal to $80 \% 19$.

According to the Program for Humanization of Prenatal Care and Childbirth of the Brazilian Ministry of Health, adequate prenatal care should begin by the $4^{\text {th }}$ month, with a total of six visits: one in the first trimester, two in the second trimester, and three in the third trimester 20 .

Villar et al. ${ }^{21}$ define adequate prenatal care in low-risk pregnancies as beginning before the $12^{\text {th }}$ week, plus three more visits: one from the $25^{\text {th }}$ to $27^{\text {th }}$ gestational week, one from the $31^{\text {st }}$ to $33^{\text {rd }}$ week, and another from the $37^{\text {th }}$ to $39^{\text {th }}$ week.

Coutinho et al. 8 define adequacy in level I as prenatal care initiated by the $14^{\text {th }}$ week and a total of six prenatal visits.

Carvalho \& Novaes ${ }^{9}$ modified the Brazilian Ministry of Health index 18 by defining adequate prenatal care as seven or more visits, including one more in the third trimester. 
Considering all the variables needed to construct the indices, a database was developed with information keyed into SPSS version 12.0 (SPSS Inc., Chicago, USA). Before keying in, the study forms were reviewed by a researcher to analyze the data completeness and consistency, providing feedback to the field interviewers, after which the data were keyed in by a professional statistician. After keying in the data, the same researcher checked the database against the forms. Finally, the researcher and statistician conducted a joint final review, checking all the variables from the forms against the database.

The statistical analyses were performed by calculating the prevalence of adequacy in relation to the criteria in each index, with the respective confidence intervals. Next, the Kappa and prevalence-adjusted Kappa tests were performed in PEPI version 4.0 (Computer Programs for Epidemiologists; http://www.sagebrushpress. $\mathrm{com} / \mathrm{pepi}$ ) to measure the levels of agreement, as follows according to Landis \& Koch 22: almost perfect agreement $(0.80-1.00)$, substantial $(0.60$ 0.79 ), moderate (0.41-0.59), fair (0.21-0.40), and slight $(\leq 0.20)$.

The study also calculated the sensitivity, specificity, positive and negative predictive values, accuracy, and positive and negative likelihood ratios in relation to the reference standard. The relationship between sensitivity and specificity was evaluated by the Receiver Operator Characteristic Curve (ROCC), which provides calculations of the area under the curve to measure the discriminant power of the indices. The Kotelchuck index ${ }^{19}$ was adopted as the reference for comparison because it is one of the most widely used indicators in studies on the evaluation of prenatal care 7,23 and has already demonstrated better performance than the oldest international index, by Kessner et al. 11 .

\section{Results}

From a total of 1,131 postpartum women that were contacted, 1,035 agreed to participate in the study and were interviewed. However, among the latter, 23 had not received any prenatal care and 6 had received prenatal care but did not have their Prenatal Cards with them, so a total of 1,006 cards were evaluated. In order to standardize the data to compose the indices, the information was used for the 1,006 postpartum women that were interviewed and that had the Prenatal Card with them.

All the indices selected to evaluate the adequacy of access to prenatal care included in their criteria at least one visit before the $5^{\text {th }}$ month of pregnancy. The other criteria considered the total number of visits, the proportion of visits in relation to gestational age, timing of visits at specific moments in the pregnancy, and number of visits according to parity.

According to the indices, the results that qualify access to adequate prenatal care showed major variations. According to the Takeda index 18, nearly $60 \%$ of the women had adequate access, while the index proposed by Rosen et al. 17 showed less than $1 \%$ adequacy. Most of the indices showed adequate access to prenatal care ranging from $20 \%$ to $50 \%$ (Table 1 ).

Table 2 shows the statistics for the kappa and adjusted kappa tests, highlighting the indices that showed substantial and almost perfect adjusted agreement. The Kessner index 11 showed adjusted kappa greater than 0.60 with the largest number of other indices. The indices proposed by Coutinho et al. 8, Villar et al. 21, and Carvalho \& Novaes ${ }^{9}$ showed high agreement with four indices, while the Takeda index 18 and Kotelchuck index 19 showed the lowest agreement with the other indices.

The Kotelchuck index 19 showed a $26 \%$ median prevalence of access to adequate prenatal care (95\%CI: 23.2-28.9) and has been cited as a reference for evaluation among the other indices. Table 3 shows the results of the comparison of the other indices to the Kotelchuck index ${ }^{19}$. The Takeda index ${ }^{18}$ presented the highest sensitivity, i.e., with the highest capacity to detect adequate access to prenatal care, while the Rosen index 17 showed the lowest capacity to classify adequate prenatal care as compared to the reference.

The Rosen index 17 showed the highest specificity, i.e., the greatest capacity to detect inadequate access to prenatal care, while the Ciari Jr. index 10 and Takeda index 18 showed specificities of around $60 \%$.

The Kessner index 1, Alexander \& Cornely index 16, and Villar index 21 showed the highest true positive rates among women with adequate prenatal care, corresponding to the highest positive predictive values. Meanwhile, the Takeda index 18 showed the highest proportion of true negatives among women with inadequate access to prenatal care, corresponding to the lowest negative predictive value (Table 3 ).

In relation to the proportion of correct answers in the evaluation of adequate access to prenatal care, the Kessner index 11 showed the highest accuracy, more than $90 \%$. The Carvalho \& Novaes index 9 , Villar index 21 , and Ministry of Health index 20 also presented high accuracy (around 80\%) (Table 3).

In the analyses of the positive likelihood ratio, the Alexander \& Cornely index 16 showed the best 
Table 1

Prevalence of adequate access to prenatal care according to different evaluation indices and their assessment criteria. Greater Metropolitan Vitória, Espírito Santo State, Brazil, 2010.

\begin{tabular}{|c|c|c|c|c|}
\hline Evaluation indices & Criteria & $\mathbf{n}$ & $\%$ & $95 \% \mathrm{Cl}$ \\
\hline \multirow[t]{3}{*}{ Ciari Jr. et al. 10 (total = 937) } & Adequate prenatal care & 483 & 51.5 & 48.3-54.7 \\
\hline & One visit in the 1 st trimester & 503 & 53.7 & $50.5-56.9$ \\
\hline & Minimum $80 \%$ ratio between visits conducted and five expected visits & 875 & 93.4 & $91.8-95.0$ \\
\hline \multirow[t]{3}{*}{ Kessner et al. 11 (total = 937) } & Adequate prenatal care & 176 & 18.8 & $16.3-21.3$ \\
\hline & One visit before the $4^{\text {th }}$ month & 503 & 53.7 & $50.5-56.9$ \\
\hline & Minimum of nine visits & 224 & 23.9 & $21.2-26.6$ \\
\hline \multirow[t]{3}{*}{ Alexander \& Cornely ${ }^{16}($ total $=937)$} & Adequate prenatal care & 41 & 4.4 & $3.1-5.7$ \\
\hline & One visit before the $4^{\text {th }}$ month & 503 & 53.7 & $50.5-56.9$ \\
\hline & $\begin{array}{l}\text { Adequate proportion between gestational age, visits conducted, and expected } \\
\text { visits }\end{array}$ & 107 & 11.4 & $9.4-13.5$ \\
\hline \multirow[t]{4}{*}{ Rosen et al. 17 (total = 937) } & Adequate prenatal care & 5 & 0.5 & $0.1-1.0$ \\
\hline & One visit by the $8^{\text {th }}$ gestational week & 77 & 8.2 & $6.5-10.0$ \\
\hline & $\begin{array}{l}\text { Primiparous women with adequate proportion between gestational age, visits } \\
\qquad \text { conducted, and visits expected }\end{array}$ & 36 & 3.8 & 2.6-5.1 \\
\hline & $\begin{array}{l}\text { Multiparous women with adequate proportion between gestational age, visits } \\
\qquad \text { conducted, and visits expected }\end{array}$ & 13 & 1.4 & $0.6-2.1$ \\
\hline \multirow[t]{3}{*}{ Takeda 18 (total = 937) } & Adequate prenatal care & 523 & 55.8 & $52.6-59.0$ \\
\hline & One visit by the $20^{\text {th }}$ week & 707 & 75.5 & $72.7-78.2$ \\
\hline & Minimum six visits & 615 & 65.6 & $62.6-68.7$ \\
\hline \multirow[t]{3}{*}{ Kotelchuck 19 (total = 933) * } & Adequate prenatal care & 243 & 26.0 & $23.2-28.9$ \\
\hline & One visit by the 4th month & 673 & 72.1 & $69.3-75.0$ \\
\hline & Minimum $80 \%$ ratio between visits conducted and expected visits & 261 & 28.0 & 25.1-30.9 \\
\hline \multirow[t]{4}{*}{ Brazil 20 (total $=937$ ) } & Adequate prenatal care & 318 & 33.9 & $30.9-37.0$ \\
\hline & One visit in the 1 st trimester & 503 & 53.7 & $50.5-56.9$ \\
\hline & Two visits in the $2^{\text {nd }}$ trimester & 687 & 73.3 & $70.5-76.2$ \\
\hline & Three visits in the 3 rd trimester & 618 & 66.0 & $62.9-69.0$ \\
\hline \multirow[t]{5}{*}{ Villar et al. 21 (total = 937) } & Adequate prenatal care & 71 & 7.6 & $5.9-9.3$ \\
\hline & One visit before the $12^{\text {th }}$ week & 301 & 32.1 & 29.1-35.1 \\
\hline & One visit in the $25^{\text {th }}, 26^{\text {th }}$, or $27^{\text {th }}$ week & 359 & 38.3 & $35.2-41.4$ \\
\hline & One visit in the 31 st, 32 nd, or 33 rd week & 588 & 62.8 & $59.7-65.8$ \\
\hline & One visit in the $37^{\text {th }}, 38^{\text {th }}$, or 39 th week & 619 & 66.1 & $63.0-69.1$ \\
\hline \multirow[t]{3}{*}{ Coutinho et al. 8 (total = 937) } & Adequate prenatal care & 383 & 40.9 & $37.7-44.0$ \\
\hline & One visit by the $14^{\text {th }}$ week & 452 & 48.2 & $45.0-51.4$ \\
\hline & Six or more visits & 615 & 65.6 & $62.6-68.7$ \\
\hline \multirow[t]{4}{*}{ Carvalho \& Novaes 9 (total $=937$ ) } & Adequate prenatal care & 200 & 21.3 & $18.7-24.0$ \\
\hline & One visit in the 1 st trimester & 503 & 53.7 & $50.5-56.9$ \\
\hline & Two visits in the 2 nd trimester & 687 & 73.3 & $70.5-76.2$ \\
\hline & Four visits in the 3 rd trimester & 368 & 39.3 & $36.1-42.4$ \\
\hline
\end{tabular}

* Variation in totals due to lack of essential information to construct the indices in some cases.

$95 \% \mathrm{Cl}$ : $95 \%$ confidence interval.

result, with odds of approximately 25 . This means that the likelihood of qualifying access to prenatal care as adequate was higher in women who actually received adequate prenatal care, when compared to qualifying their prenatal care as adequate when it was really inadequate. Meanwhile, the Kessner index ${ }^{11}$ showed results equal to zero, meaning that the odds were nil of diagnosing adequate prenatal care among women who actually received inadequate care (Table 3 ).

As for negative likelihood ratios, shown in Table 3 , the Takeda index 18 showed the lowest like- 
Table 2

Agreement among indices for access to prenatal care. Greater Metropolitan Vitória, Espírito Santo State, Brazil, 2010.

\begin{tabular}{|c|c|c|c|c|c|c|c|c|c|c|}
\hline \multirow[t]{2}{*}{ Indices } & \multicolumn{10}{|c|}{ Adjusted kappa coefficients } \\
\hline & (a) & (b) & (c) & (d) & (e) & (f) & (g) & (h) & (i) & (j) \\
\hline \multicolumn{11}{|l|}{ Kappa coefficients * } \\
\hline (a) Ciari Jr. et al. 10 & 1 & 0.34 & 0.05 & -0.02 & 0.63 ** & 0.38 & $0.61 * \star$ & 0.12 & 0.79 ** & 0.38 \\
\hline (b) Kessner et al. 11 & 0.36 & 1 & $0.68 * \star$ & $0.62 * \star$ & 0.26 & $0.83 * \star$ & $0.60 * *$ & $0.71 \star \star$ & 0.53 & $0.77^{* \star}$ \\
\hline (c) Alexander \& Cornely 16 & 0.08 & 0.25 & 1 & 0.92 & -0.05 & 0.55 & 0.34 & $0.80 * \star$ & 0.25 & 0.58 \\
\hline (d) Rosen et al. 17 & 0.01 & 0.00 & 0.13 & 1 & -0.11 & 0.48 & 0.31 & 0.84 ** & 0.19 & 0.56 \\
\hline (e) Takeda 18 & 0.63 & 0.31 & 0.06 & 0.01 & 1 & 0.40 & 0.53 & 0.03 & 0.70 ** & 0.30 \\
\hline (f) Kotelchuck 19 & 0.39 & 0.76 & 0.19 & -0.01 & 0.43 & 1 & 0.58 & 0.59 & 0.54 & $0.60 * *$ \\
\hline (g) Brazil 20 & 0.62 & 0.50 & 0.07 & -0.01 & 0.55 & 0.51 & 1 & 0.44 & 0.71 & $0.75^{\star *}$ \\
\hline (h) Villar et al. 21 & 0.14 & 0.38 & 0.09 & -0.01 & 0.12 & 0.32 & 0.23 & 1 & 0.33 & 0.60 ** \\
\hline (i) Coutinho et al. 8 & 0.79 & 0.47 & 0.10 & 0.02 & 0.71 & 0.50 & 0.69 & 0.21 & 1 & 0.51 \\
\hline (j) Carvalho \& Novaes 9 & 0.39 & 0.64 & 0.11 & -0.01 & 0.35 & 0.53 & 0.69 & 0.23 & 0.46 & 1 \\
\hline
\end{tabular}

* All Kappa tests statistically significant at $p<0.05$;

** Adjusted agreement levels $\geq 0.60$.

Table 3

Comparison of Kotelchuck index to other indices for access to prenatal care. Greater Metropolitan Vitória, Espírito Santo State, Brazil, 2010.

\begin{tabular}{|c|c|c|c|c|c|c|c|c|c|c|}
\hline \multirow[t]{2}{*}{ Indices } & \multirow[t]{2}{*}{ Assessment } & \multicolumn{2}{|c|}{ Kotelchuck 19} & \multirow[b]{2}{*}{ Sensitivity } & \multirow[b]{2}{*}{ Specificity } & \multicolumn{2}{|c|}{ Statistics } & \multirow[b]{2}{*}{ Accuracy } & \multirow[b]{2}{*}{ PLR } & \multirow[b]{2}{*}{ NLR } \\
\hline & & Adequate & Inadequate & & & PPV & NPV & & & \\
\hline \multirow[t]{2}{*}{ Ciari Jr. et al. 10} & Adequate & 217 & 265 & 89.3 & 61.6 & 45.0 & 94.2 & 68.8 & 2.33 & 0.17 \\
\hline & Inadequate & 26 & 425 & & & & & & & \\
\hline \multirow[t]{2}{*}{ Kessner et al. 11} & Adequate & 171 & 5 & 70.4 & 99.3 & 97.2 & 90.5 & 91.7 & 0.00 & 0.30 \\
\hline & Inadequate & 72 & 685 & & & & & & & \\
\hline \multirow[t]{2}{*}{ Alexander \& Cornely 16} & Adequate & 35 & 4 & 14.4 & 99.4 & 89.7 & 76.7 & 77.3 & 24.85 & 0.86 \\
\hline & Inadequate & 208 & 686 & & & & & & & \\
\hline \multirow[t]{2}{*}{ Rosen et al. 17} & Adequate & 1 & 3 & 0.4 & 99.6 & 25.0 & 74.0 & 73.8 & 1.00 & 0.99 \\
\hline & Inadequate & 241 & 686 & & & & & & & \\
\hline \multirow[t]{2}{*}{ Takeda 18} & Adequate & 242 & 280 & 100.0 & 59.4 & 46.4 & 100.0 & 69.9 & 2.46 & 0.00 \\
\hline & Inadequate & 0 & 409 & & & & & & & \\
\hline \multirow[t]{2}{*}{ Brazil 20} & Adequate & 183 & 135 & 75.3 & 80.4 & 57.5 & 90.2 & 79.1 & 3.85 & 0.31 \\
\hline & Inadequate & 60 & 555 & & & & & & & \\
\hline \multirow[t]{2}{*}{ Villar et al. 21} & Adequate & 62 & 9 & 25.6 & 98.7 & 87.3 & 79.1 & 79.7 & 19.61 & 0.75 \\
\hline & Inadequate & 180 & 680 & & & & & & & \\
\hline \multirow[t]{2}{*}{ Coutinho et al. 8} & Adequate & 206 & 176 & 85.1 & 74.5 & 53.9 & 93.4 & 77.2 & 3.33 & 0.20 \\
\hline & Inadequate & 36 & 513 & & & & & & & \\
\hline \multirow[t]{2}{*}{ Carvalho \& Novaes 9} & Adequate & 142 & 58 & 58.4 & 91.6 & 71.0 & 86.2 & 83.0 & 6.95 & 0.45 \\
\hline & Inadequate & 101 & 632 & & & & & & & \\
\hline
\end{tabular}

NLR: negative likelihood ratio; NPV: negative predictive value; PLR: positive likelihood ratio; PPV: positive predictive value.

lihood of classifying prenatal care as inadequate in women with adequate care, as compared to women with truly inadequate care. This means that the odds of a false-inadequate assessment of prenatal care were zero.
According to the assessment of the indices by ROCC in Figure 1, in the relationship between sensitivity and specificity, the largest areas below the lines were for the indices proposed by Kessner et al. 11 (0.848), Coutinho et al. 8 (0.798), Takeda 18 


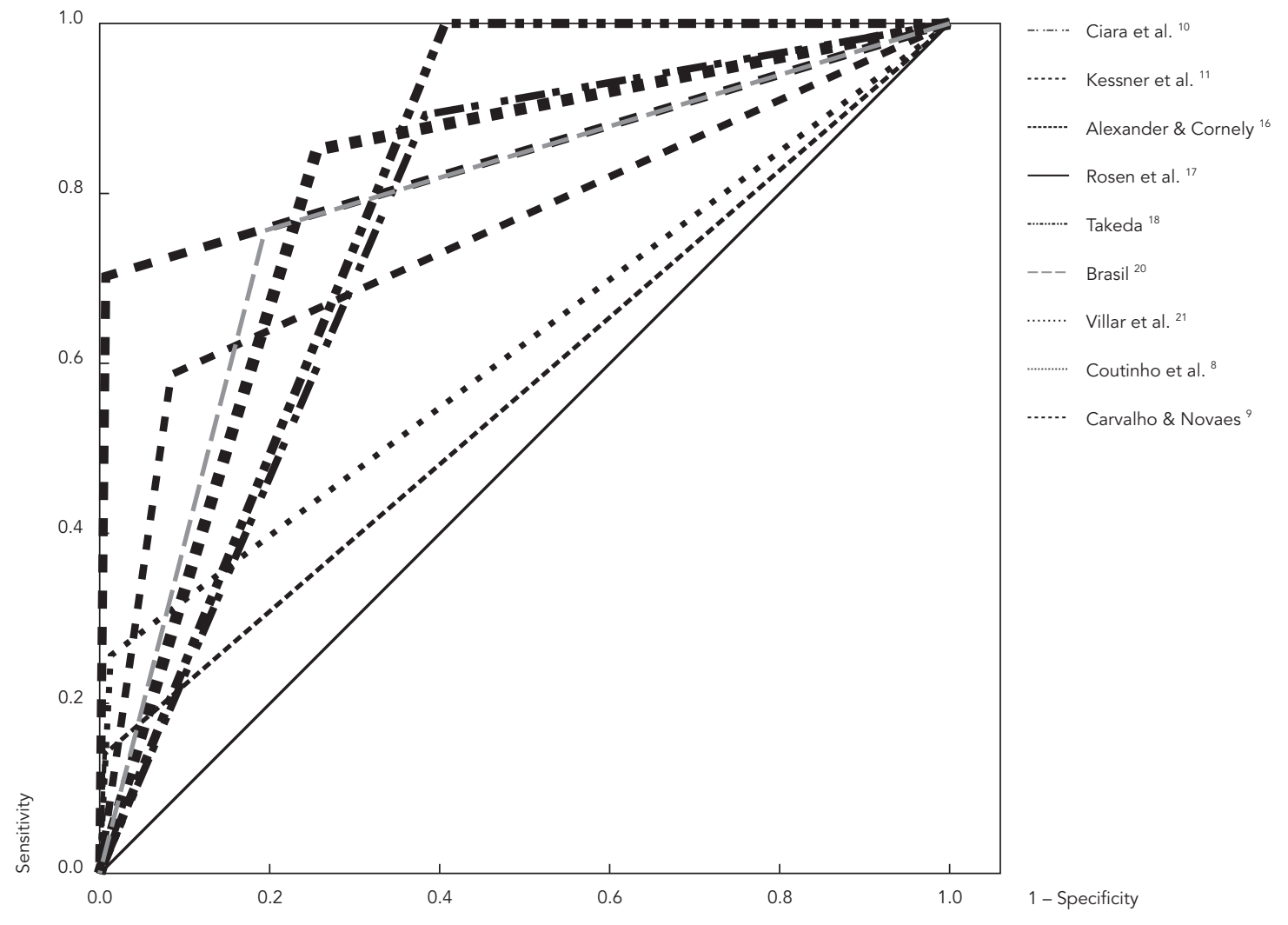

(0.797), and the Ministry of Health 20 (0.781). The indices proposed by Ciari Jr. et al. $10(0.755)$ Carvalho \& Novaes 9 (0.751), and Villar et al. 21 (0.622) showed intermediate values. The indices with the lowest areas were Alexander \& Cornely 16 (0.567) and Rosen et al. 17 (0.500), reflecting the low capacity of these indices to discriminate between adequate and inadequate access to prenatal care.

\section{Discussion}

Access to prenatal care in health services allows pregnant women and their infants to enjoy greater likelihood of survival. In the contact between pregnant women and healthcare teams, diseases and risk situations can be diagnosed and then treated or minimized 24. However, the prenatal care that produces such effects must be based on a process of care that includes the main activities for the prevention or pregnancy-related diseases and health promotion 6 .

Process of care that is consistent with the health needs of pregnant women depends primarily on adequate access to prenatal follow-up. However, public health has faced a major challenge in defining indices to assess adequate access to prenatal care. Some authors base their indices on the association with unfavorable maternal and infant outcomes, such as: maternal mortality, low birth weight, preeclampsia, gestational hypertension, caesarean delivery, among others 4 . Others assess adequacy of care on the basis of the mothers' level of satisfaction 5 .

Importantly, the indices are developed by an author or group of authors within specific contexts. The Kessner 11, Alexander \& Cornely 16, Rosen et al. 17, and Kotelchuck 19 indices were developed in the social and historical context of 
the United States, mixing political, scientific, and economic interests allied with the defense of the lucrative exploitation of the predominantly private healthcare market.

The Ciari Jr. index 10 emerged from the pioneering Brazilian academic experience of standardizing prenatal care in an academic health center, as did the Takeda index ${ }^{18}$. Meanwhile, the Brazilian Ministry of Health index 20 was created on the basis of the political decision in defense of the right to maternal and child health in the SUS. The Coutinho ${ }^{8}$ and Carvalho \& Novaes 9 indices appeared as academic variations on the previous index, proposing an evaluation of the policy's functioning in public healthcare services.

The Villar index 21 deals with the effort by the World Health Organization to standardize and reduce the costs of low-risk prenatal care using scientific criteria, aimed at reducing the number of maternal and infant deaths, as well as gestational and postpartum diseases and complications.

However, the choice of an index to assess adequate access to prenatal care has direct repercussions on maternal and child health policies, as long as the results of the assessment provide support for changes in the reality of health services. The current study demonstrates that the prevalence of adequacy according to the indices is highly variable. A change in only one criterion in the index can greatly increase or decrease the prevalence of adequate access to prenatal care, as occurred with the Ministry of Health 20 and Carvalho \& Novaes 9 indices.

These prevalence rates also decrease considerably when the criteria classify adequate care according to the number of visits in relation to gestational age 16 or with few visits but at welldefined gestational weeks 21 . On the other hand, when a deadline is set for initiating prenatal care and only the total number of visits is considered, regardless of the gestational age at which they occur, the prevalence of adequacy increases greatly, as with the Takeda index 18 .

This phenomenon allows questioning which strategy would be the most effective for the health of the mother and infant: many visits versus few visits at specific periods in the pregnancy. Studies in various countries have shown that the reduction in the number prenatal visits was not associated with any negative perinatal or maternal outcome 25. However, in countries with low and medium development, perinatal mortality is higher among women with few prenatal visits 4 . More visits may increase the possibility of performing tests and clinical procedures.

Other authors conclude that the level of satisfaction is higher among women with more en- counters with healthcare teams during pregnancy ${ }^{5}$. Still, the costs of complete prenatal care with few visits is much lower for the health system 4,25 . At the same time, mean length of stay in neonatal intensive care units is much shorter for children of mothers with more prenatal visits 5 . There is no consensus on the ideal number of visits, but most of the indices defined adequate care as including a minimum of four visits (Table 1).

In public health services, the organization of qualified access for low-risk mothers during few visits could provide a strategy to reduce costs. This would free up health professionals for closer follow-up of high-risk pregnant women, who require more visits due to their pregnancy-related conditions and complications 26. Meanwhile, during pregnancy, women are more receptive to the incorporation of new knowledge 27 that can be transformed into healthier practices. Thus, more frequent contacts with health services through prenatal visits serve as a health-promoting educational opportunity, especially with group activities.

Even considering more than nine visits as the criterion for adequacy of term gestations, the Kotelchuck index 19 demonstrated that the other indices evaluated in this study showed intermediate adequacy. In addition, it enjoys the analytical advantage of classifying prenatal care in pregnancies that end in premature deliveries, considering the proportion of prenatal visits in relation to gestational age.

Importantly, the Kotelchuck index 19 defines adequacy as more visits than are provided for according to Brazil's official prenatal care policy 20 . In this sense, the current study was limited by having applied the Kotelchuck index in prenatal follow-up conducted exclusively within the SUS. However, the Ministry of Health index 20 did not show a higher prevalence of adequacy (as should have been expected), and demonstrated moderate adjusted agreement with the Kotelchuck index 19. This suggests that Brazilian women in the SUS are having more prenatal visits than provided for by the official policy.

The Kessner index 11 showed the highest levels of adjusted agreement with six other indices. This can be explained by the early prenatal uptake criterion, which includes the initiation of prenatal care from the other indices and increases the possibilities for more visits by the woman. It was also the index with the highest accuracy. Still, it appears coherent to consider that parity should be an important criterion for evaluating access to prenatal care, since multiparous women, with their longer childbearing histories, may present unfavorable conditions that have already been diagnosed previously, while women in their first 
pregnancy are inexperienced and may be unaware of the risk conditions for their own health and that of their infants, as proposed by Rosen et al. ${ }^{17}$.

The modified GINDEX 16, which includes an important number of prenatal visits according to gestational age, and the Rosen index 17, which includes quite specific gestational intervals for performing the visits, lead to low power for discriminating between adequate and inadequate prenatal care. The Villar index 21 also showed low discriminant power, because it is only used to assess low-risk pregnancies. The current study considered low-risk and high-risk pregnancies indistinctly, but high-risk pregnancies require more visits, even with late initiation. In this case, the criteria for adequacy would be met for the majority of the indices. The indices used in the current study apply mainly to low-risk pregnancies, since high-risk pregnancies require a combination of prenatal care methods adapted to each woman's systemic condition.

Although indices that time the beginning of prenatal care and provide looser scheduling of visits have shown higher discriminant power 8,18, a positive aspect appears to be the definition of gestational periods that are not excessively strict for scheduling visits, as proposed by the Ministry of Health 20 and Carvalho \& Novaes 9 indices. The evaluation strategies provided these indices with a good relationship between sensitivity and specificity, with high levels of accuracy for adequately classifying prenatal care.

However, these indicators are limited by the fact that they cannot be used to assess prenatal follow-up of pregnancies with premature outcomes, or for prenatal care already under way. Another limitation of these indices is that fail to consider socioeconomic and demographic characteristics, social support, other reproductive variables, the supply of services by health services, including the availability of services within a given geographic territory 28 , the prevailing model of care, and the links between levels of care.

Tamez-Gonzalez et al. 30 analyzed some of these elements, including predisposing, mediating, and health-needs factors to assess social inequality in access to prenatal care in Mexico
City. Likewise, Ribeiro et al. ${ }^{30}$ concluded that socioeconomic inequalities, demographic factors, and risk behaviors are associated with inadequate prenatal care.

Another limitation is that the selected indices are unable to assess the adequacy of each prenatal visit's content, including the package of services required for properly qualified visits, which include certain clinical procedures and tests, since the study's focus was only adequacy of access to prenatal care.

\section{Conclusion}

Indices for the assessment of access to prenatal care differ from each other. This leads to different prevalence rates for adequacy of prenatal care in Greater Metropolitan Vitória, varying according to the index used to assess maternal and child health.

In general, levels of agreement between the indices were less than 0.60 and related to the criteria for constructing each indicator. In addition, these levels are higher when the criteria are more similar and allow early initiation of prenatal care in the assessment.

Indices that consider initiation of prenatal care by the fourth month and number of visits according to trimesters as criteria for defining adequacy show higher discriminant power, that is, a good relationship between sensitivity and specificity, in addition to higher accuracy. However, health services should be open to pregnant women accessing the system when they perceive the need for care.

Based on a critical reflection, the study concludes that the Carvalho \& Novaes index 8 and the Brazilian Ministry of Health index 20 are relevant for assessing adequacy of access to prenatal care.

The conclusions that generally provide the basis for diagnoses can direct the reorganization of maternal and child health services to implement policies for the prevention of diseases and health promotion for women and children. The use of different indices to assess adequacy of access thus produce distinct results. 


\section{Resumen}

El objetivo de este estudio fue comparar la evaluación de la adecuación del acceso a la atención prenatal por diferentes indices. Información para los indices que componen fueron tomadas de 1.006 formularios de encuestas, las tarjetas y los registros médicos de mujeres embarazadas que fueron hospitalizadas durante el parto en la maternidad Gran Vitória Metropolitana, Espírito Santo, Brasil, en el período de abril a septiembre de 2010. Los índices de evaluación de la atención prenatal se compara con el índice Kotelchuck (1994), el patrón de referencia. La prevalencia de adecuación se calcularon y se analizan de acuerdo, los coeficientes de sensibilidad, especificidad, exactitud predictiva, y la probabilidad se realizaron. La mayor prevalencia de adecuación fue encontrado por Takeda índice (55,8\%). El mayor acuerdo se estableció entre las tasas de Villar et al y Rosen et al (ajustado kappa =0,84). Llegamos a la conclusión de que el índice y el índice de Carvalho y Novaes y el Ministerio de Salud de Brasil son pertinentes para evaluar la adecuación del acceso a la atención prenatal.

Salud Materno-Infantil; Evaluación em Salud; Servicios de Salud Materno-Infantil; Accesibilidad a los Servicios de Salud

\section{Contributors}

E. T. Santos Neto participated in the study planning and design, data collection and analysis, interpretation of the results, and writing and revision of the manuscript. A. E. Oliveira contributed to the study planning and design, interpretation of the results, and writing and revision of the manuscript. E. Zandonade participated in the study planning and design, data analysis, interpretation of the results, and writing and revision of the manuscript. M. C. Leal participated in the study planning, interpretation of the results, and writing and revision of the manuscript.

\section{Acknowledgments}

The authors wish to thank FAPES for the research funding.

\section{References}

1. Foucault M. Microfísica do poder. 18 $\mathrm{a}$ Ed. Rio de Janeiro: Edições Graal; 1979.

2. Pontes RJ, Ramos-Júnior AN, Kerr LRS, Bosi MLM. Transição demográfica e epidemiológica. In: Medronho RA, Bloch KV, Luiz RR, Werneck GL. Epidemiologia. 2a Ed. São Paulo: Editora Atheneu; 2009. p. 123-52.

3. Wehby GL, Murray JC, Castilla EE, Lopez-Camelo JS, Ohsfeldt RL. Prenatal care effectiveness and utilization in Brazil. Health Policy Plan 2009; 24: 175-88.

4. Dowswell T, Carroli G, Duley L, Gates S, Gülmezoglu AM, Khan-Neelofur D, et al. Alternative versus standard packages of antenatal care for low-risk pregnancy. Cochrane Database Syst Rev 2010; (6):CD000934
5. Carroli G, Carroli G, Villar J, Piaggio G, Khan Neelofur D, Gülmezoglu M, et al. WHO systematic review of randomised controlled trials of routine antenatal care. Lancet 2001; 19:1565-70.

6. World Health Organization. What is the effectiveness of antenatal care? Copenhagen: WHO Regional Office for Europe; 2005.

7. Leal MC, Gama SGN, Ratto KMN, Cunha CB. Uso do índice de Kotelchuck modificado na avaliação da assistência pré-natal e sua relação com as características maternas e o peso do recém-nascido no Município do Rio de Janeiro. Cad Saúde Pública 2004; 20 Suppl 1:S63-72. 
8. Coutinho T, Teixeira MTB, Dain S, Sayd JD, Cou tinho LM. Adequação do processo de assistência pré-natal entre as usuárias do Sistema Único de Saúde em Juiz de Fora-MG. Rev Bras Ginecol Obstet 2003; 25:717-24.

9. Carvalho DS, Novaes HMD. Avaliação da implantação de programa de atenção pré-natal no Município de Curitiba, Paraná, Brasil: estudo em coorte de primigestas. Cad Saúde Pública 2004; 20 Suppl 2:S220-30.

10. Ciari Jr. C, Santos JLF, Almeida PAM. Avaliação quantitativa de serviços de pré-natal. Rev Saúde Pública 1972; 6:361-70.

11. Kessner DM, Singer J, Kalk CE, Schlesinger ER. Infant death: an analysis by maternal risk and health care: contrasts in health status. Washington DC: Institute of Medicine, National Academy of Science; 1973.

12. Amorim MMR, Melo ASO. Avaliação dos exames de rotina no pré-natal (parte 1). Rev Bras Ginecol Obstet 2009; 31:148-55.

13. Amorim MMR, Melo ASO. Avaliação dos exames de rotina no pré-natal: parte 2. Rev Bras Ginecol Obstet 2009; 31:367-74.

14. Andersen RM. Revisiting the behavioral model and access to medical care: does it matter? J Health Soc Behav 1995; 36:1-10.

15. Handler A, Issel M, Turnock B. A conceptual framework to measure performance of public health system. Am J Public Health 2001; 91:1235-9.

16. Alexander GR, Cornely DA. Prenatal care utilization: its measurement and relationship to pregnancy outcome. Am J Prev Med 1987; 3:243-53.

17. Rosen MG, Merkatz IR, Hill JG. Caring for our future: a report by the Expert Panel on the Content of Prenatal Care. Obstet Gynecol 1991; 77:782-7.

18. Takeda S. Avaliação de unidade de atenção primária: modificação dos indicadores de saúde e qualidade da atenção [Dissertação de Mestrado]. Pelotas: Universidade Federal de Pelotas; 1993.

19. Kotelchuck M. An evaluation of Kessner adequacy of prenatal care index and a proposed adequacy of prenatal care utilization index. Am J Public Health 1994; 84:1414-20.

20. Brasil. Portaria no 569, de 1 de junho de 2000. Institui o Programa de Humanização no Pré-natal e Nascimento no âmbito do SUS. Diário Oficial da União 2000; 8 jun.
21. Villar J, Ba'aqeel H, Piaggio G, Lumbiganon $P$, Miguel BJ, Farnot U, et al. WHO antenatal care randomised trial for the evaluation of a new model of routine antenatal care. Lancet 2001; 357:1551-64.

22. Landis JR, Koch GG. The measurement of observer agreement for categorical data. Biometrics 1977; 33:159-74.

23. Beeckman, Louckx F, Masury-Stroobant G, Downe S, Putman K. The development and application of a new tool to assess the adequacy of the content and timing of antenatal care. BMC Health Serv Res $2011 ; 11: 213$.

24. Menezes EV, Yakoob MY, Soomro T, Haws RA, Darmstadt GL, Bhutta ZA. Reducing stillbirths: prevention and management of medical disorders and infections during pregnancy. BMC Pregnancy Childbirth 2009; 7 Suppl 1:S4.

25. Villar J, Carroli G, Khan-Neelofur D, Piaggio G, Gülmezoglu M. Patterns of routine antenatal care for low-risk pregnancy. Cochrane Database Syst Rev 2001; (4):CD000934.

26. Departamento de Ações Programáticas Estratégicas, Secretaria de Atenção à Saúde, Ministério da Saúde. Gestação de alto risco: manual técnico. 5a Ed. Brasília: Editora do Ministério da Saúde; 2010.

27. Costa ICC, Marcelino G, Berti GM, Saliba NA. A gestante como agente multiplicador de saúde. RPG Rev Pos-Grad 1998; 5:87-92.

28. Melo EC, Mathias TAF. Spatial distribution and self-correlation of mother and child health indicators in the State of Parana, Brazil. Rev Latinoam Enferm 2010; 18:1177-86.

29. Tamez-Gonzalez S, Valle-Arcos RI, EibenschutzHartman C, Mendez-Ramirez I. Adaptación del modelo de Andersen al contexto mexicano: acceso a la atención prenatal. Salud Pública Méx 2006; 48:418-29.

30. Ribeiro ER, Guimarães AM, Bettiol H, Lima DD, Almeida ML, Souza L, et al. Risk factors for inadequate prenatal care use in the metropolitan area of Aracaju, Northeast Brazil. BMC Pregnancy Childbirth 2009; 9:31.

Submitted on 27/Aug/2012

Final version resubmitted on 09/Feb/2013

Approved on 08/Mar/2013 